Journal of Education and Educational Development

8(2), 296-318, 2021

DOI: http://dx.doi.org/10.22555/joeed.v8i2.443

\title{
Exploring the Causes of Plagiarism among Post Graduate Research Students- A Phenomenological Case Study Approach
}

\author{
Munir Moosa Sadruddin \\ Sindh Madressa-tul-Islam University, Pakistan
}

\begin{abstract}
The phenomenological case study aimed to unearth the reasons that influence university students to plagiarize assignments. 67 participants were selected for semistructured interviews, from the Faculty of Education of a public university, located in Karachi, Pakistan. The obtained data were analyzed through thematic analysis. Findings uncovered that most participants lacked a deep understanding of different types of academic plagiarism and practical skills to evade it. Prevalent sources of information for preparing assignments included websites, research papers, e-books, and project reports, without verifying quality. The most common reasons that have influenced research students to plagiarize assignments included weak language and academic writing skills, easy access to online resources, conventional assignments, inadequate digital literacy, short time-frame, and challenge to balance personal, professional, and academic life. Thus, plagiarism is a conscious act coupled with indirect pressures. It is recommended to promote the culture of academic honesty among learners. In this regard, courses on preventing plagiarism, digital literacy, academic reading, and research writing should be integrated as a pre-requisite for a postgraduate research degree. It is also proposed to help learners embrace conscious networking skills and ownership of learning. Furthermore, contextual information literacy and plagiarism frameworks should be introduced.
\end{abstract}

Keywords: academic dishonesty, plagiarism, research students

\section{Introduction}

Oxford Dictionary defines plagiarism as 'the practice of taking someone else's work or ideas and passing them off as one's own (2020). It is an intellectual theft, where a person claims false authorship. The prevalence of plagiarism is a 
growing concern for higher education institutions across cultures (Ison, 2018; Jereb et al., 2018; Montoneri, 2020; Nelson, 2017; Pecorari \& Shaw 2018; Velliaris, 2016). However, it is complex to find the actual reasons that engage learners to commit plagiarism due to its multifaceted nature.

One of the prevalent factors for plagiarism is technology. A wide range of literature confirms the preceded claim (Anney \& Mosha, 2015; Bailey, 2015; Farooq \& Haroon, 2014; Levine \& Pazdernik, 2018; Selemani et al., 2018; Šprajc et al., 2017). However, a few studies did not hold technology accountable, rather, view it as an approach to curtail plagiarism (Fatima et al., 2018; Peytcheva-Forsyth et al., 2018). Local studies are sparse to support the former and the latter claims.

Another pertinent reason is lack of knowledge. A few studies support the preceded claim (Abbasi et al., 2020; Bašić et al., 2018; Elshafei \& Jahangir, 2020; Idiegbeyan-ose et al., 2016; Memon et al., 2019; Murtaza et al., 2013; Ramzan et al., 2012). However, the questions arise, is there any association between awareness and the incidence of plagiarism? Are learners equipped with skills to curtail plagiarism? These, alongside other elements, need to be explored to comprehend the actual reasons.

Culture can stimulate learners to plagiarize assignments. For example, in East Asian countries, 'collective culture' i.e., sharing others' work or ideas is considered a good practice. Similarly, the memorization of ideas and imitating philosophical concepts are preferred. Sowden (2005; as cited in Martin, 2011) stated, "[In] Asian educational orientations... students copy 'experts' as a reproduction of established knowledge is the norm, as opposed to innovation based on the educational material presented" (p.262). However, Strangfeld (2019) believes that culture has no significant impact on dishonesty because plagiarism is a strategy that emerges at least in part out of social inequalities students faced within the larger educational system. For example, in Pakistan, cultural values refrain people from all forms of dishonesty. Despite this, plagiarism among Pakistani university students is growing. It is predicted that plagiarism stems from the traditional educational practices, class hierarchies, and weak educational background, which somehow has not been probed by the previous studies. 
The theory of cultural relativism is pertinent to the present research context. Rather than traditional cultural practices, it looks at culture through the lens of individuals' beliefs, practices, and values (EBSCO Information Services, 2009). Another applicable theory is the theory of reasoned action. It states, "A person's behavior is determined by their intention to perform the behavior and that this intention is, in turn, a function of their attitude toward the behavior and subjective norms" (Fishbein \& Ajzen, 1975, p. 128).

Other studies have highlighted social and inadequate language skills, time constraints, academic pressures, inadequate ideas, lack of confidence, competition, fear of failure, limited skills, scant awareness, and lack of policy intervention as determinants (Abbasi et al., 2020; Cleary, 2017; Dergisi, 2017; Farahian et al., 2020; Hopp \&Speil, 2020; Husain et al., 2017; Jereb et al., 2017; Memon \& Mavrinac, 2020; Moss et al., 2017).

Higher Education Commission of Pakistan (HEC) - a national regulatory body of educational institutions have emphasized promoting research culture across the higher education institutions (HEIs). However, universities remain unproductive to reap quality research output. Academic malpractice, i.e., copy and pastealso continues to grow across HEIs due to unfledged research culture and weak policy interventions (Abbasi, 2018; Pakistan Today, 2018; Talal, 2018). One of the reports highlights, "[Due to] a weak legal system coupled with weak enforcement, the culture of promoting original work and discouraging plagiarism could not be nurtured in our higher education." (Mahmood, 2016).

Academic pressure on HEIs to produce immediate research output has compelled individuals to plagiarize content. One of the newspapers underlines, '[Due to] a pressure to 'publish or perish,' an increasing number of researchers have taken to cutting corners, resulting in falsified research, fraudulent data, paraphrasing, duplication, and blatant plagiarism' (The Nation, 2016). Similarly, Hunter (2020) expressed, 'Much of the rapid growth in Pakistan's research output is owed to an incentivization system that ties academic journal publications to faculty promotions and financial rewards. As a result, the system is said to be rife with corruption, plagiarism, and fabricated research.' 
In recent years, HEC has introduced the anti-plagiarism policy, but it has not entirely succeeded to curb academic malpractices due to multiple reasons. One of the recent local studies highlighted a lack of awareness as one of the key barriers to academic honesty (Javaid et al., 2021). Findings of another study pointed out peer pressure, memorization, and inconsistencies in the assessment method as reasons behind academic misconduct (Haq et al., 2020). Whereas, outcomes of one other study uncovered poor training, pressure, lack of skills, and self-efficacy as possible factors (Fatima et al., 2019).

Other available recent studies highlighted weak reading and comprehension skills, fear of failure, poor vigilance, poor time management skills, and lack of policy intervention as the causes of plagiarism (Bibi \& Hafeez, 2018; Javaeed et al., 2019; Yousaf et al., 2019).

Previous research studies did not explore actual reasons for practicing plagiarism among university learners due to methodological limitations. Furthermore, no critical exploration has been conducted on this subject matter during recent years. All these highlight a knowledge gap, which signifies a need to address, prevailing, gaps in the Pakistani context.

\section{About the Site}

Hundreds of students are currently pursuing a research degree in various disciplines. They have exposure to digital technology and are familiar with HEC plagiarism policy and penalties. But faculty members have been receiving piles of plagiarized assignments and dissertations the university under study is the oldest university in Karachi, Pakistan, providing quality education to approximately forty thousand in-campus students. These learners are from diverse cultural and ethnic backgrounds. Like other universities in Pakistan, teachers in this university also face the issues of student plagiarism. To give an idea, one of the faculty members, through proper consent, has shared a comparative plagiarism index of fourteen randomly checked assignments (two each).

\section{Research Question}

1. What are the reasons which influence postgraduate research students towards plagiarism? 


\section{Figure 1}

Comparative Similarity Index of Randomly Checked Assignments (Anonymous)

\begin{tabular}{|c|c|c|}
\hline $46 \%$ & E & $41 \%$ \\
\hline $50 \%$ & E & $43 \%$ \\
\hline $50 \%$ & n & $50 \%$ \\
\hline $51 \%$ & E & $51 \% \square$ \\
\hline $52 \%$ & m & $65 \% \square$ \\
\hline $52 \%$ & = & $70 \% \square$ \\
\hline $64 \%$ & E & $70 \%$ \\
\hline $65 \%$ & ש & $72 \%$ \\
\hline $66 \%$ & E & $73 \%$ \\
\hline $67 \%$ & a & $76 \%$ \\
\hline $83 \%$ & E & $78 \% \square$ \\
\hline $86 \%$ & E & $83 \%$ \\
\hline $95 \%$ & 口 & $91 \% \square$ \\
\hline $99 \%$ & ש & $92 \%$ \\
\hline
\end{tabular}

To bridge the gaps, the present study has attempted to uncover the actual reasons for plagiarism through the lens of postgraduate research students.

\section{Research Design}

Most previous studies took a quantitative survey approach to explore the phenomenon under study. The present study is situated in a qualitative research paradigm. It involves an interpretive naturalistic approach to investigating multiple phenomena subjectively; i.e., exploring learners' experiences (Denzin \& Lincoln, 2011; University of Leicester, 2019).

Within qualitative research, a phenomenon logical case study approach is adopted. Case studies are 'anchored in real-life situations and result in a holistic investigation of a particular phenomenon (Merriam, 2009; Yin, 2014). An explanatory case study is selected to gather data from a single academic institution. One of its strengths is capturing contextual data from limited participants. Secondly, it often involves a combination of multiple methods to validate findings (The Open University, 2019). But there are a few limitations like the researcher may guide participants or interpret data (Flyberrg, 2011). This issue is addressed through Bennett's model of intercultural sensitivity (Bennett, 2012). On the other hand, phenomenology looks for the commonality of an individual's personal lived experience (Creswell, 2013). A descriptive phenomenological study is undertaken to gather lived experiences through firsthand knowledge (Patton, 2014). One of its 
strengths is holistically capturing human experiences. Narratives provide insights to build a sense of connectivity (Gerrish et al., 2015). There are a few limitations like participants might not share personal experiences. To mitigate, the researcher has refrained from intriguing personal information, rather pioneered and adapted a 'reflective expressive free flow approach'. It is assumed that phenomenology does not produce reliable data due to the limited sample size. However, Remeyni et al. (1998) express that phenomenological data is reliable as it describes what is directly perceived than interpretations.

For this study, the phenomenological case study approach is fused with to explore the context-based experiences of learners at one of the public sector university. It has engaged researchers in what Michael Agar (1996) calls the "funnel approach" to fieldwork Flyberrg underlined, "A purely descriptive, without any attempt to generalize can certainly be of value in this process and has often helped cut a path toward scientific innovation" $(2011$, p.6).

\section{Sampling}

67 post-graduate research students were selected through multi-stage sampling; i.e., criterion and convenient sampling techniques from the Faculty of Education of ABC University during the semester 'Fall 2019'. Multi-stage sampling has helped to identify relevant participants in the context of geographical proximity, to gather in-depth information.

\section{Data Collection}

Previous studies explored the reasons for plagiarism through questionnaires, focus group discussions, and interviews. Data for this study is collected through indepth phenomenon logical semi-structured interviews. Creswell (2013) underlines that in-depth interviews are sufficient to reach saturation in a phenomenological study. Interview questions are validated through construct validity and the expert's opinion. To ensure construct validity, the interview questionnaire was piloted with some potential participants. Final interviews were conducted face-to-face. Interviews were audio-record and transcribed.

\section{Data Analysis}

Data is analyzed through thematic analysis. It is consistent with 
phenomenological criteria as set by Giorgi (2009). The researcher has followed thematic analysis phases as proposed by Braun \& Clarke (2006), and Hofstede's Cultural Dimensions Theory (Hofstede, 2011) to rate research design. Whereas credibility of findings is assessed through the criteria set by Lincoln \& Guba (2006). Discussion is appended within data analysis.

\section{Findings and Discussion}

All the coding was done manually and the initial codes were datadriven. Coding was sorted to derive potential themes. To avoid subjective data interpretations, to validate findings, and to mediate power relations, participants received a copy of transcribed data, as suggested by Dillon (2014).

Academic dishonesty has become widespread across the universities in Pakistan. However actual reasons are kept under the carpet. Findings of two previous local studies claimed a low level of awareness, weak knowledge, and negative perception as the factors influencing plagiarism (Murtaza et al., 2013; Ramzan et al., 2012). However, no sufficient evidence is gathered to deem it as a reason for plagiarism.

To evaluate the awareness and knowledge of participants towards plagiarism, I asked them a few general questions. All the participants were familiar with the term 'plagiarism. According to them, copying/using others' ideas from the internet without acknowledgment or citing reference, or claiming it as on work is plagiarism. It is worth noting that all participants linked plagiarism only with online resources. The researcher further inquired about familiarity with types of academic plagiarism, referencing, and paraphrasing skills, none agreed with the former, but a few participants expressed that they possess skills for the latter. When asked, if they ever attended any physical or online training to avoid plagiarism, none of them concurred. It is noteworthy that nearly all participants were aware of its consequences. Mostly expressed that albeit they know about plagiarism policy, penalties remain fictitious. The preceded expressions predict to have motivated students towards plagiarism.

Most of the participants confessed that they switched to the research degree in education as they could not qualify for the field of their choice, and had no other option left. More than half of the research students had taken a gap of about five 
years or more before resuming studies. A good number of them desire to acquire a higher position at the workplace after the completion of a research degree, whilst a few want to complete doctoral studies from abroad. The gap in studies, considering a research degree in education as a last resort, and a strong desire for the materialistic benefits could have led them towards plagiarizing assignments.

Following themes were derived from the interviews.

\section{Language Barrier}

English is used as the second language in Pakistan. The medium of instruction in nearly all Pakistani universities is English. However, the language of instruction remains a challenge due to linguistic differences across Pakistani cultures (Asif et al., 2020). Waqar (2020) quoted, "Power and inequality are often tied in with teaching English in Pakistan. As a student, the quality of instruction you receive is often dependent on your socio-economic circumstances".

Nearly all had completed the previous schooling from the public institutions and attained the last degree either as an external (private) or distance learning candidate, where English was not the compulsory medium of instruction. Only a few had finished their earlier schooling from private institutions with English as a teaching language. Most of them disclosed that it is challenging to prepare assignments in English because of the language barrier. One of them shared:

"I am weak at translating ideas in English. Even if I try, it is difficult to meet academic standards".

Another participant unveiled:

"When I start preparing assignments, my mind goes blank. I can hardly write a paragraph. I don't know, but English remains a blockade to my success".

A few participants disclosed that plagiarism has helped to maintain good grades. One of them expressed:

"Most of the time, it is difficult to express ideas in your own words. I don't 
care about plagiarism unless it is caught. All I want is to maintain a good GPA. That is why I prefer copying online data".

Another participant shared a similar perspective:

"I am not good at English. I requested my tutors to allow me to prepare assignments in Urdu (The national language of Pakistan), but he refused. As a solution, I once bought old academic books from the market and copied everything. I also added fake references to impress tutors. No one detected that! I am practicing the same these days".

The preceded expressions highlight weak language skills as one of the factors. These views are supported by Martin (2011), who underlined that Asian students are tempted to intentionally plagiarize due to limited exposure to second language skills. Pecorari (2015) seconded, and expressed that plagiarism is practiced by international students, who write through the medium of a second language.

Parallel to the latter, through narratives, the researcher identified the barrier of teaching language, and the desire to maintain good grades as factors of plagiarism. Educational inequities towards educational preparedness are also evident. Local literature is sparse to generalize the claim, yet these findings are significant towards understanding language as one of the barriers in the given context.

\section{Weak Academic and Research Writing Skills}

When inquired about the previous exposure to preparing assignments, a good number of them, particularly those who had completed their previous education as an external (private) candidate, pooled that they had no earlier exposure to preparing assignments. However, seventeen had completed their prior education as regular or distance learning candidates and had the experience of preparing assignments. Despite this, mostly disclosed that they had plagiarized assignments because of weak writing skills. One participant said:

"Earlier, I prepared many handwritten assignments as a distance education student. I copied all as I am weak at academic writing. No one bothered about the quality. I just had to meet the formalities". 
None of the participants had previously attended any academic and research writing course or workshop to improve research writing skills. Credit courses on academic and research writing are not offered at the postgraduate level in the education department of the selected university. The situation is quite deplorable across Pakistan. When asked if they are given guidelines on preparing academic assignments, nearly all disagreed. Participants expressed their grief that tutors expect them to prepare quality assignments, without exposing them to research writing courses.

One of the participants admitted:

"During the last semester, I prepared assignments for the first time. I am still confused about how to cite sources. Without proper guidance, I am tempted to copy and paste from the internet".

Another participant exclaimed:

"I don't know how to incorporate evidence in academic writing. I am also not familiar with referencing and paraphrasing resources. So I prefer gathering literature from the internet, and meshing it to make it look original."

One more participant expressed similar views:

"I am neither good at sentence formation nor paragraph writing. Whenever I start preparing an assignment, I feel less confident".

One of the participants shed light on his previous exposure and current expectations:

"When I joined this university, I had no or little understanding of preparing a research-based assignment. I expected to improve my academic writing skills, but no course or support was offered".

Two participants revealed that they use online paraphrasing software to conceal plagiarism, whereas four participants disclosed that they get paid assignments to cope up with weak academic writing skills. One of them voluntarily admitted: 
"I have hired the services of an expert, who charges a decent amount against preparing assignments. It has helped me to maintain good grades".

Views expressed by participants coincide with Javaid et al. (2021), who underlines that students end up plagiarizing when they lack knowledge about the norms of academic and research writing. Similarly, findings from another study revealed poor writing skills as one of the reasons for plagiarism (Chankova, 2017). A few local research studies and reports have highlighted the prevalence of weak research and academic writing culture, and critical thinking skills among Pakistani university learners (Ahmed, 2017; Fareed et al., 2016; Irfan, 2019; Mahesar, 2020; Nauman, 2017).

A few participants also disclosed that they are unable to write well due to weak reading skills, and so they prefer replicating the text. They lack content knowledge that halts them from preparing justified assignments. One of them informed:

"During schooling, we were habitual to learning essays, paragraphs, applications, and letters by heart-word to word. Now, at the university level, we lack critical reading practices. Our tutors provide us with reading materials, but critical reading skills remain a question mark”.

Thus, weak academic writing skills and a lack of provision of academic writing courses have surged academic malpractices.

\section{Conventional Assignments}

When inquired about the nature of assignments received, most of them expressed that the assignments were theoretical and descriptive. Only a few participants shared that it was critical, collaborative, or research-based. Nearly all participants were dissatisfied with the assignment topics. They also had no idea of the criteria for checking assignments. They were in view that the topics were traditionally crafted. One of them said:

"Most of the assignments were theoretical. Let me share an example of the assigned topic- 'Define research and what the types of research are? "How can I write something new, when the tutors asked us to focus on 
conventional knowledge?

Another participant complained:

"Tutors have demanded us to add lots of references, and discouraged us to share experiences. I once added real-life examples that were not well appreciated".

These views reverberate with traditional educational practices. In East Asian countries, learners are taught to memorize ideas as a form of respect for scholars and are discouraged to produce innovative and integrative work.

Participants reported that common, traditional assignment topics have illprepared them for future research work. They also unveiled that tutors replicate the assignment topics that were given to the previous batches. One of them stated:

"Teachers decide on assignments topics. Students are not allowed to make a collective decision and suggest any topic. We are discouraged from the openness of ideas and participation. Certainly, it is good to plagiarize and avoid any clash of ideas with tutors".

When asked if they have access to plagiarism detection tools, all disagreed. Whilst a few previous research studies have highlighted the positive impact of using digital interventions like anti-plagiarism software to mitigate plagiarism (Buckley \& Cowap, 2013; Köse \& Arikan, 2011; Mphahlele \& McKenna, 2019; Sarwar et al., 2016), some have shed light on its limitations. For example, Walchuk (2016) underlines that software is costly and inaccessible to all. Secondly, it is ineffective to assess semantic plagiarism and cannot detect open licensure and translated documents.

Nearly all participants disclosed that the lack of feedback from the tutors has kept them away from identifying mistakes to improve work. One of the participants reported,

"Tutors should look into the nature of the assignment that lacks quality and clarity. I am here to learn and grow, but how? Faculty members have never 
returned my assignment with feedback. How can I improve my writing skills, if I am kept blindfolded? I predict they discard our work into the trash".

Six students conveyed that during the last semester, they received a few critical assignments from one of the tutors that were hard to cheat. One of them explained,

"One of our tutors gave us assignments based on class discussions and critical readings. He also encouraged us to use a local context and examples to explore the topics. Further, he guided us on how to prepare a researchbased assignment."

One of the studies highlighted assignment strategies and structures such as collaborative work, collecting field notes, and reflection as an effective approach to deter plagiarism (Heckler et al., 2013). Whereas, another study proposed an instructional approach towards formative assessment as beneficial for students learning (Leung \& Cheng, 2017).

Overall, conventional assignments with no or less feedback and one-sided decisions on assignment topics have compelled participants towards plagiarism.

\section{Assignment Load, Commitments, and Short Time Frame}

Most of the participants complained about their struggle with balancing academic, personal, and professional commitments. They were offered a postgraduate research degree on weekends. However, they expressed difficulty completing assignments within a short time frame. Each tutor gives weekly or fortnightly assignments that, in their view are difficult to complete. One of the participants mourned:

"Three assignments a week is unacceptable. It is difficult to balance, social, personal, and professional life. The management has turned deaf ear to our permissible demands. We are left with plagiarizing assignments to meet tutors'demands".

Participants complained that tutors deduct marks on late submission. To meet deadlines, plagiarism is used as the easiest route. One of the participants said: 
"I use a combination of scripts and images to conceal plagiarism. Had we received fewer assignments, we would have tried to sustain the quality of submitted work".

One of the female participants justified:

"I plagiarize assignment due to extensive workload ofjob, house chores, and personal issues. Such responsibilities and short notice to submit assignment have forced me to plagiarize work".

Few participants voiced that there is no clear policy on the frequency of assignments. Each tutor makes their own decision without taking the learners' consent. One of them expressed:

"I have the right to plagiarize because of short deadlines and heavyworkload. I mostly prepare my assignments a day before the class. Sometimes, I had to collect soft copies of previous assignments from senior fellows, and submit the same".

Former data concurred with the findings of the study conducted by Fatima et al. (2019). Findings of another study underlined that student "workload has both direct and indirect effects through academic procrastination on attitude to plagiarize" (Ismail et al., 2014, p.4).

Thus, pressure to submit the assignment within the given deadline and excessive workload have potentially inclined participants towards plagiarism.

\section{Easy Access to Online Resources}

Participants confirmed that they have digital skills and access to the internet and digital devices. However, they validated that the HEC has provided them access to the digital library with sparse content on social sciences. They spend an average of 3 hours a week on the internet for preparing assignments. One of them disclosed that the use of private online groups has made it easy to plagiarize assignments. He expressed: 
"HEC is fooling around with the research students. Most of the social sciences content is inaccessible except abstracts. I mostly copy and paste resources from private blogs and Facebook closed groups. It helps to reduce chances of being caught".

Another participant claimed:

"I collect a few online reports and newspaper articles that are easily accessible, and cut the relevant information to prepare good assignment".

A few previous studies support the latter claim. Šprajc et al. (2017) carried out survey research to discover the reasons behind plagiarism among students of the University of Maribor, Slovenia. Easy access to online resources is identified as the most common cause. Similarly, Jereb et al. (2018) carried out a comparative study to find the difference, and factors influencing plagiarism among German and Slovene university students. Easy access to the web was highlighted as the main factor. Selemani et al. (2018) uncovered reasons for plagiarism from the postgraduate students at Mzuzu University, Malawi. The majority of respondents highlighted the ease of copying online content as one of the factors. However, local research studies are unavailable.

The main sources of gathering information to prepare assignments by the participants include websites, followed by online books, Wikipedia, websites, research papers, Urdu books, newspaper articles, online presentations, blogs, e-book, institutional learning management systems, and project reports. When queried about the strategy to confirm the authenticity of online resources, nearly all expressed that their tutors have suggested using an online resource for reference purposes. One of the participants responded,

"Internet is the authentic medium because the resources are published on websites or other online platforms, so it is unlikely that people will keep unreliable online resources".

Growing cases of plagiarism and the participant's responses reflect that they lack digital literacy, i.e., using the internet contextually and appropriately to make the most out of it. The researcher can relate the learning journey of participants to the concept of Visitors and Residents (White \& Cornu, 2011). They started their 
online journey as a visitor but failed to turn out as a resident of digital learning.

In short, participants use a variety of resources to complete the assignment without verification of its authenticity. Intentional plagiarism was also surfaced from narratives.

\section{Conclusion and Recommendations}

The rise in the cases of plagiarism is a menace to the sustenance of academic integrity. It needs more than knowledge, skills, and technology to tackle this challenge. Looking at the menace of academic dishonesty through an ethnographic lens could be the possible mediator. HEC seeks the collective efforts of all stakeholders to find a solution to plagiarism. Therefore, it is imperative to review the existing policy and devise a sustainable plan of action in light of research findings. Furthermore, research students need digital literacy to combat plagiarism, which can be intervened by the university management.

Contextual information literacy and plagiarism framework should be designed through the adaptation of global frameworks and applied at the university level for the ethical use of information. Practices of fictitious penalties should be curtailed.

Few studies have highlighted the positive impact of awareness sessions on reducing plagiarism (Levine \&Pazdernik, 2018; Obeid \& Hill, 2017; Shang, 2019). A hands-on training session on digital literacy to develop a sense of ownership is suggested. Also, it is pertinent to help students embrace an identity as a researcher through self-identity exploration. Introducing a combination of interventions like policy implementation, anti-plagiarism software, digital literacy, research training can help lessen plagiarism.

\section{References}

Abbasi, P., Yoosefi-Lebni, J., Jalali, A., Ziapour, A., \& Nouri, P. (2020). Causes of the plagiarism: A grounded theory study. Nursing Ethics, 28(2), 282-296. https://doi. org/10.1177\%2F0969733020945753

Abbasi, W. (2018, April 30). Major plagiarism in two books of ex-chairman of HEC. The News International. https://www.thenews.com.pk/print/310749-major-plagiarism- 
in-two-books-of-ex-chairman-of-hec

Agar, M. (1996). The professional stranger: An informal introduction to ethnography (2nd ed). Academic Press.

Ahmed, M. Z. (2017). Enough quantity: Time to focus on quality of researchers in Pakistan. International Higher Education, 91, 24-25. http://dx.doi.org/10.6017/ ihe.2017.91.9744

Anney, V. N., \& Mosha, M. A. (2015). Student's plagiarisms in higher learning institutions in the era of improved internet access: Case study of developing countries. Journal of Education and Practice, 6(13), 203-260.

Asif, S., Afzal, I., \& Bashir, R. (2020). An analysis of medium of instruction policies in the education system of Pakistan with specific reference to English medium education. Sir Syed Journal of Education and Social Research, 3(2), 370-382. https://doi.org/10.36902/sjesr-vol3-iss2-2020(370-382)

Bailey, J. (2015). The impact of social media on plagiarism. Plagiarism Today. https://www. plagiarismtoday.com/2015/06/04/the-impact-of-social-media-on-plagiarism/

Bašić, Ž., Kružić, I., Jerković, I., Buljan, I., \& Marušić, A. (2018). Attitudes and knowledge about plagiarism among university students: Cross-sectional survey at the University of Split, Croatia. Science and Engineering Ethics, 25(5), 1467-1483. https://doi.org/10.1007/s11948-018-0073-x

Bennett, J. M. (2012). The developing art of intercultural facilitation. Building Cultural Competence: Innovative Activities and Models, 13, 205-226.

Bibi, T., \& Hafeez, A. (2018). Exploration of plagiarism practices in Open and Distance Learning (ODL). Journal of Distance \& Online Learning, 4(1), 49-62.

Braun, V., \& Clarke, V. (2006). Using thematic analysis in psychology. Qualitative Research in Psychology, 3(2), 77-101. https://core.ac.uk/download/pdf/1347976.pdf.

British Educational Research Association (2011). Ethical guidelines for educational research. Retrieved from https://www.bera.ac.uk/wp-content/uploads/2014/02/ BERA-Ethical-Guidelines-2011.pdf?noredirect=1

Buckley, E., \& Cowap, L. (2013). An evaluation of the use of Turnitin for electronic submission and marking and as a formative feedback tool from an educator's perspective. British Journal of Educational Technology, 44(4), 562-570. https:// doi.org/10.1111/bjet.12054

Chankova, M. (2017). Dealing with students' plagiarism pre-emptively through teaching proper information exploitation. International Journal for the Scholarship of Teaching and Learning, 11(2).

Chavez, C. (2008). Conceptualizing from the inside: Advantages, complications, and 
demands on insider positionality. The Qualitative Report, 13(3), 474-494.

Cleary, M. (2017). Top 10 reasons students plagiarize \& what teachers can do about it (with apologies to David Letterman). Phi Delta Kappan, 99(4), 66-71. https://doi. org/10.1177/0031721717745548

Creswell, J. (2013). Qualitative inquiry and research design: Choosing among five approaches. SAGE.

Denzin, N., \& Lincoln, Y. (2011). The SAGE handbook of qualitative research (5th ed.). SAGE.

Dillon,M.(2014).AFoucauldian analysis of power relations in anaction research study.Action Research, 12(2), 209-223. https://doi.org/10.1177\%2F1476750314529598

EBSCO Information Services. (2009). Cultural Relativism. Retrieved from https://www. ebscohost.com/uploads/imported/thisTopic-dbTopic-1247.pdf

Elshafei, H., \& Jahangir, T. (2020). Factors affecting plagiarism among students at Jazan University. Bulletin of the National Research Centre, 44(1). https://doi.org/10.1186/ s42269-020-00313-z

Farahian, M., Parhamnia, F., \& Avarzamani, F. (2020). Plagiarism in theses: A nationwide concern from the perspective of university instructors. Cogent Social Sciences, 6(1). https://doi.org/10.1080/23311886.2020.1751532

Fareed, M., Ashraf, A., \& Bilal, M. (2016). ESL Learners' writing skills: Problems, factors and suggestions. Journal of Education \& Social Sciences, 4(2), 83-94.

Fatima, A., Sunguh, K., Abbas, A., Mannan, A., \& Hosseini, S. (2019). Impact of pressure, self-efficacy, and self-competency on students' plagiarism in higher education. Accountability in Research, 27(1), 32-48. https://doi.org/10.1080/089 89621.2019 .1699070

Farrow, R. (2016). A framework for the ethics of open education. Open Praxis, 8(2). http:// dx.doi.org/10.5944/openpraxis.8.2.291

Farooq, U., \& Haroon, M. Z. (2014). Plagiarism in scientific writing. Journal of Ayub Medical College Abbottabad-Pakistan, 26(4).

Fatima, A., Abbas, A., Ming, W., Hosseini, S., \& Zhu, D. (2018). Internal and external factors of plagiarism: Evidence from Chinese public sector universities. Accountability in Research, 26(1), 1-16. https://doi.org/10.1080/08989621.2018.1552834

Fishbein, M., \& Ajzen, I. (1975). Belief, attitude, intention, and behavior. Addison-Wesley.

Flyberrg, B. (2011). Five misunderstandings about case-study research. In P. Atkinson \& S. Delamont, SAGE Qualitative Research Methods. SAGE.

Gerrish, K., Lathlean, J., \& Cormack, D. (2015). The research process in nursing (7th ed). Wiley-Blackwell. 
Giorgi, A. (2009). The descriptive phenomenological method in psychology: A modified Husserlian approach. Pittsburgh: Duquesne University Press.

Government of Pakistan (2018). Personal Data Protection Bill 2018. Government of Pakistan. Retrieved from https://moitt.gov.pk/userfiles1/file/PERSONAL-DATAPROTECTION-BILL-July-18-Draft.pdf

Haq, A., Mahmood, S., Shabbir, M., \& Batool, Z. (2020). Assessing the academic integrity among university students in Pakistan. Journal of Business and Social Review in Emerging Economies, 6(3), 1025-1032. https://doi.org/10.26710/jbsee.v6i3.1359

Heckler, N., Forde, D., \& Bryan, C. (2013). Using writing assignment designs to mitigate plagiarism. Teaching Sociology, 41(1), 94-105.

Hofstede, G. (2011). Dimensionalizing cultures: The Hofstede Model in context. Online Readings in Psychology and Culture, 2(1).

Hopp, C., \& Speil, A. (2020). How prevalent is plagiarism among college students? Anonymity preserving evidence from Austrian undergraduates. Accountability in Research, 28(3), 133-148. https://doi.org/10.1080/08989621.2020.1804880

Hunter, R. (2020). Education in Pakistan. World Education News + Reviews. Retrieved from https://wenr.wes.org/2020/02/education-in-pakistan

Husain, F., Al-Shaibani, G., \& Mahfoodh, O. (2017). Perceptions of and attitudes toward plagiarism and factors contributing to plagiarism: A review of studies. Journal of Academic Ethics, 15, 167-195.

Idiegbeyan-ose, J., Nkiko, C., \& Osinulu, I. (2016). Awareness and perception of plagiarism of postgraduate students in selected universities in Ogun State, Nigeria. Library Philosophy and Practice, 1322. Retrieved from https://digitalcommons.unl.edu/ cgi/viewcontent.cgi?article $=3557 \&$ context=libphilprac

Irfan, H. (2019). The policy and practice of English medium of instruction (EMI) in Pakistani universities. Cambridge Scholars Publishing.

Ison, D. (2018). An empirical analysis of differences in plagiarism among world cultures. Journal of Higher Education Policy and Management, 40(4), 291-304.

Ismail I. R., Zulkifli N., Pauzi S. F. M., Hadi K. A. A., \& Najid N. A. (2014). Effects of Student Workload and Academic Procrastination on Attitude to Plagiarize: A Partial Least Squares Application. In A. Kasim, W. Wan Omar, N. Abdul Razak, N. Wahidah Musa, R. Ab. Halim, \& S. Mohamed (Eds.). Proceedings of the International Conference on Science, Technology and Social Sciences (ICSTSS) 2012. Springer. https://doi.org/10.1007/978-981-287-077-3_43

Javaid, S., Sultan, S., \&Ehrich, J. (2021). Contrasting first and final year undergraduate students' plagiarism perceptions to investigate anti-plagiarism measures. Journal 
of Applied Research in Higher Education, 13(2), 561-576. https://doi.org/10.1108/ JARHE-04-2020-0080

Javaeed, A., Khan, A.S., Khan, S.H., \&Ghauri, S.K. (2019). Perceptions of plagiarism among undergraduate medical students in Rawalpindi, Pakistan. Pakistan Journal of Medical Sciences, 35(2).https://doi.org/10.12669/pjms.35.2.33

Jereb, E., Perc, M., Lämmlein, B., Jerebic, J., Urh, M., Podbregar, I., \&Šprajc, P. (2018). Factors influencing plagiarism in higher education: A comparison of German and Slovene students. PLOS ONE, 13(8). https://doi.org/10.1371/journal.pone.0202252 Jereb, E., Urh, M., Jerebic, J., \&Šprajc, P. (2017). Gender differences and the awareness of plagiarism in higher education. Social Psychology of Education, 21(2), 409-426. https://doi.org/10.1007/s11218-017-9421-y

Köse, Ö., \&Arikan, A. (2011). Reducing plagiarism by using online software: An experimental study. Contemporary Online Language Education Journal, 1, 122129. https://files.eric.ed.gov/fulltext/ED524097.pdf

Leung, C. H., \& Cheng, S. C. (2017). An instructional approach to practical solutions for plagiarism. Universal Journal of Educational Research, 5(9), 1646-1652. https:// files.eric.ed.gov/fulltext/EJ1170133.pdf

Levine, J., \& Pazdernik, V. (2018). Evaluation of a four-prong anti-plagiarism program and the incidence of plagiarism: a five-year retrospective study. Assessment \& Evaluation in Higher Education, 43(7), 1094-1105. https://doi.org/10.1080/02602 938.2018.1434127

Lincoln, Y., \& Guba, E. (2006). Naturalistic inquiry. Newbury Park: SAGE.

Mahesar, R. (2020, January 12). Research culture in Pakistani universities. Daily Times. Retrieved from https://dailytimes.com.pk/537876/research-culture-in-pakistaniuniversities/

Mahmood, K. (2016). Overall assessment of the higher education sector. Retrieved from https:/hec.gov.pk/english/universities/projects/TESP/Documents/FR-Assessment $\% 20$ HE\%20Sector.pdf.

Martin, D. (2011). Culture and unethical conduct: Understanding the impact of individualism and collectivism on actual plagiarism. Management Learning, 43(3), 261-273. https://doi.org/10.1177\%2F1350507611428119

Memon, A., \& Mavrinac, M. (2020). Knowledge, attitudes, and practices of plagiarism as reported by participants completing the Author AID MOOC on research writing. Science and Engineering Ethics, 26(2), 1067-1088. https://doi.org/10.1007/ s11948-020-00198-1 
Memon, R., Ali, M., Zafar, M., \& Shaikh, A. (2019). Knowledge and attitude towards plagiarism: a comparative study of students from medical and non-medical fields. Journal of Global Health Reports, 3(7). https://doi.org/10.29392/ joghr.3.e2019067

Moss, S., White, B., \& Lee, J. (2017). A systematic review into the psychological causes and correlates of plagiarism. Ethics \& Behavior, 28(4), 261-283. https://doi.org/1 0.1080/10508422.2017.1341837

Mphahlele, A., \& McKenna, S. (2019). The use of turnitin in the higher education sector: Decoding the myth. Assessment \& Evaluation in Higher Education, 44(7), 10791089. https://doi.org/10.1080/02602938.2019.1573971

Murtaza, G., Zafar, S., Bashir, I., \& Hussain, I. (2013). Evaluation of students perception and behavior towards plagiarism in Pakistani universities. Acta Bioethica, 19(1), 125-130. https://doi.org/10.4067/s1726-569x2013000100013

Nauman, S. (2017). Lack of critical thinking skills leading to research crisis in developing countries: A case of Pakistan. Learned Publishing, 30(3), 233-236. https://doi. org/10.1002/leap.1091

Obeid, R., \& Hill, D. (2017). An intervention designed to reduce plagiarism in a research methods classroom. Teaching of Psychology, 44(2), 155-159. https://doi. org/10.1177\%2F0098628317692620

Oxford Dictionary. (2020). Definition of plagiarism. Retrieved from https:// en.oxforddictionaries.com/definition/plagiarism.

Pakistan Today. (2018, March 2). HEC is investigating 59 plagiarism cases: report. Pakistan Today. Retrieved from https://www.pakistantoday.com.pk/2018/03/02/ hec-is-investigating-59-plagiarism-cases-report/.

Patton, M. (2014). Qualitative research \& evaluation methods: Integrating theory and practice. SAGE.

Pecorari, D. (2015). Plagiarism, International students and the second-language writer. In T. Bretag (Ed.). Handbook of academic integrity (pp.537-550). Springer. https://doi.org/10.1007/978-981-287-079-7_69-2

Peytcheva-Forsyth, R., Aleksieva, L., \& Yovkova, B. (2018). The impact of technology on cheating and plagiarism in the assessment - The teachers' and students' perspectives. In 44th International Conference on Applications of Mathematics in Engineering and Economics. AIP Conference Proceedings. https://aip.scitation. org/doi/pdf/10.1063/1.5082055.

Ramzan, M., Munir, M., Siddique, N., \& Asif, M. (2012). Awareness about plagiarism amongst university students in Pakistan. Higher Education, 64(1), 73-84. https:// 


\section{doi.org/10.1007/s10734-011-9481-4}

Remeyni, D., Williams, B., Money, A., \& Swartz, E. (1998). Doing research in business and management: An introduction to process and method. SAGE.

Sarwar, M., Moin, M., \& Jabeen, M. (2016). Role of plagiarism detecting software in reducing academic dishonesty at M.Phil level. The Dialogue, 11(4), 122-129.

Selemani, A., Chawinga, W., \& Dube, G. (2018). Why do postgraduate students commit plagiarism? An empirical study. International Journal for Educational Integrity, 14(1), 1-15. https://doi.org/10.1007/s40979-018-0029-6

Shang, H. (2019). An investigation of plagiarism software use and awareness training on English as a foreign language (EFL) students. Journal of Computing in Higher Education, 31(1), 105-120.

Šprajc, P., Urh, M., Jerebic, J., Trivan, D., \&Jereb, E. (2017). Reasons for plagiarism in higher education. Organizacija, 50(1), 33-45. https://doi.org/10.1515/orga-20170002

Strangfeld, J. (2019). I just don't want to be judged: Cultural capital's impact on student plagiarism. SAGE Open, 9(1). https://doi.org/10.1177/2158244018822382

Talal, S. (2018). Don't be fooled by Pakistan topping the 'World's Highest Rise in Research Output' List for 2018. Retrieved from https://propakistani.pk/2018/12/24/dontbe-fooled-by-pakistan-topping-the-worlds-highest-rise-in-research-output-listfor-2018/

The Nation. (2016, June 14). Plagiarism in Pakistan. The Nation. Retrieved from https:// nation.com.pk/14-Jun-2016/plagiarism-in-pakistan

The Open University. (2019). How to collect and analysenon-numerical data. Retrieved from https://learn2.open.ac.uk/mod/oucontent/view.php?id=1402088\&section=1.4

University of Leicester. (2019). Qualitative versus quantitative approaches to gathering evidence [podcast].https://learn2.open.ac.uk/mod/oucontent/view. php?id=1402087\&section $=1.3$

Velliaris, D. M. (2016). Handbook of research on academic misconduct in higher education. IGI Global.

Walchuk, K. (2016). An examination of the efficacy of the plagiarism detection (Masters Dissertation). Institute of Technology, University of Ontario.

Waqar, K. (2020, May 15). The English in our classrooms. Dawn Newspaper. Retrieved from https://www.dawn.com/news/1555239/the-english-in-our-classrooms

White, D. S., \& Cornu, A. (2011). Visitors and Residents: A new typology for online engagement. First Monday, 16(9).https://doi.org/10.5210/fm.v16i9.3171

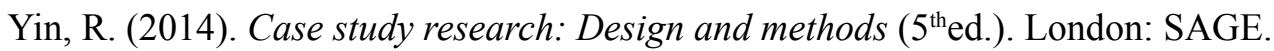


Yousaf, A., Iqbal, S., \& Yousaf, F. (2019). Attitude of Management students toward plagiarism and cheating: A Survey of University of the Punjab. Retrieved from https://www.researchgate.net/publication/337439495_Attitudes_of_Students Towards_Cheating_and_Plagiarism_A_Survey_of_University_of_Pakistan 